\title{
Topic Study Group No. 42: Uses of Technology in Lower Secondary Mathematics Education (Age 10-14)
}

\author{
Lynda Ball, Paul Drijvers, Bärbel Barzel, Yiming Cao \\ and Michela Maschietto
}

There is no doubt that digital technology nowadays has a tremendous impact on society. As a consequence, the question arises as to what impact this has on the teaching and learning of mathematics. The ICME-13 Topic Study Group «Uses of technology in lower secondary mathematics education» addressed this topic for education to $10-14$ year olds and aimed to:

- establish an overview of the current state of the art in technology use in mathematics education, including both practice-oriented experiences and research-based evidence, as seen from an international perspective;

- suggest important trends for technology-rich mathematics education in the future, including a research agenda and school level implementation strategies.

This focus is related to the topic of other ICME-13 TSGs. TSGs 41 and 43, respectively, focused on primary or upper secondary; TSG 44 addressed e-learning and blended learning. As there was one general TSG on in-service and professional development of secondary mathematics teachers (TSG 50), the TSG 42 described here included both a learner's and a teacher's perspective on digital technology in lower secondary mathematics education.

The following themes were core in the work of TSG 42 .

Co-Chairs: Lynda Ball, Paul Drijvers.

Team members: Bärbel Barzel, Yiming Cao, Michela Maschietto.

\footnotetext{
L. Ball

The University of Melbourne, Melbourne, Australia

e-mail: lball@unimelb.edu.au

P. Drijvers $(\bowtie)$

Freudenthal Institute Utrecht University, Utrecht, The Netherlands

e-mail: p.drijvers@uu.nl

(C) The Author(s) 2017

G. Kaiser (ed.), Proceedings of the 13th International Congress on Mathematical

Education, ICME-13 Monographs, DOI 10.1007/978-3-319-62597-3_69
} 
- Evidence for effect:

What are the research findings about the benefits for student learning of the integration of digital tools in lower secondary mathematics education?

- Mathematics education in 2025:

What will lower secondary mathematics education look like in 2025, with respect to the place of digital tools in curricula, teaching and learning? How can teachers integrate physical and virtual experiences to promote deep understanding of mathematics?

- Digital assessment:

What are features of appropriate online assessment of, for and as learning?

- Communication and collaboration:

How can digital technology be used to promote communication and collaborative work between students, between teachers, and between students and teachers? What are the potential professional development needs of teachers integrating digital tools into their teaching, and how can technology act as a vehicle for such professional development activities?

Even if these themes are not exhaustive for the topics of the TSG, most contributions in these proceedings focus on one of them, and as such offer an excellent overview of the advancements in this field.

Open Access Except where otherwise noted, this chapter is licensed under a Creative Commons Attribution 4.0 International License. To view a copy of this license, visit http://creativecommons. org/licenses/by/4.0/.

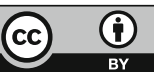

